\title{
1 Energy and Mass Balances Related to Climate Change and Remediation
}

2 Angela D. Lueking ${ }^{\mathrm{a}^{*}}$ and Milton W. Cole

$3{ }^{\mathrm{a} D e p a r t m e n t s ~ o f ~ C h e m i c a l ~ E n g i n e e r i n g, ~ E n e r g y ~ \& ~ M i n e r a l ~ E n g i n e e r i n g, ~}{ }^{\mathrm{b}}$ Department of Physics,

4 The Pennsylvania State University

5 *Corresponding Author: 120 Hosler, University Park, PA 16802, ad111@psu.edu

6 Abstract

7 The goal of this paper is to provide a forum for a broad interdisciplinary group of scientists and

8 engineers to see how concepts of climate change, energy, and carbon remediation strategies are

9 related to quite basic scientific principles. A secondary goal is to show relationships between

10 general concepts in traditional science and engineering fields and to show how they are relevant

11 to broader environmental concepts. This paper revisits Fourier's early mathematical derivation

12 of the average temperature of the Earth from first principles, i.e. an energy balance common to

13 chemical and environmental engineering. The work then uses the concept of mass balance to

14 critically discuss various carbon remediation strategies. The work is of interest to traditional

15 scientists/engineers, but also it is potentially useful as an educational document in advanced

16 undergraduate science or engineering classes.

\section{Keywords}

18 Climate model, carbon capture and storage, carbon utilization

\section{Introduction}

From artists to engineers, how does an instructor best prepare students for issues they will

21 face related to climate change, energy supply, and the nexus of these two issues? Future

22 public policy decisions may well be in the hands of those without a strong scientific

23 background. Meanwhile, as many science and engineering undergraduates are developing

24 the technical background to tackle these challenges, they may miss out on many aspects 
25 of a broader education that will put future solutions in context. To "engineer a 26 sustainable future", our undergraduates will need a broad contextual understanding of 27 energy usage, energy supply, carbon dioxide emissions, and environmental ramifications 28 of technology. Yet, topics regarding energy and the environment are much broader than 29 are typically covered in disciplinary science and engineering courses, and although these 30 topics are suitable for electives, the scientific concepts of many electives may be diluted 31 to accommodate a broader audience. Meanwhile, technical papers are often so highly 32 specialized that they may be nearly incomprehensible to those outside the immediate 33 field, at least without a significant investment of time to understand the background 34 literature.

35 Over the past three years, we have written a textbook, Science of Earth, Climate and 36 Energy, ${ }^{1}$ which is targeted to a general (non-scientific) audience. In undertaking such a 37 task, i.e. writing such a very broad overview that introduces the underlying scientific 38 concepts that govern these processes on a level accessible to a non-scientifically minded 39 citizen, the authors often found in their discussions that many of the "basic" concepts 40 should not be taken as "assumed basic knowledge" to all authors. This is perhaps 41 surprising, given that the authors of this book come from quite closely related disciplines 42 (i.e. physics and chemical engineering), and even had collaborated on a number of 43 scientific papers. If such a small subset of scientists occasionally found difficulty in 44 communicating in each other's "basic language", surely the same could likely be said for 45 a larger subset of scientists from even more divergent fields. Moreover, in asking 46 colleagues to review the book draft, and/or discussing basic tenets that came to light in its 47 writing, the authors often received comments from "expert" colleagues indicating that 
they had learned something new, or seen something from a new perspective. Surely such

49 dialogue on such an important topic has merit beyond the narrow community of educators

50 that would be teaching from a general education textbook. The purpose of this paper is to

51 repurpose the basic premises found within this general education textbook to a broader

52 technical community, including scientists and engineers that are expert within their

53 individual disciplines, but perhaps have become too focused to see the broader

54 applicability of their disciplinary science. The paper has the additional purpose of serving

55 as an introductory manuscript for advanced undergraduates to learn how issues of energy

56 and the environment are grounded in basic fundamental principles. Too often, in an effort

57 to communicate difficult concepts to the general public, some of these basic tenets may

58 become lost and not at all transparent to disciplinary scientists and engineers.

59 Anthropogenic climate change is a politically charged subject, as it has considerable 60 implications regarding how we use energy, which in turn, affects every facet of our 61 society and economy. Much attention and heated debate have been drawn to the so-called

62 "hockey stick" graph, ${ }^{2}$ which, when published in 1998, showed a long-term "global 63 warming" phenomenon. Indeed, the seven warmest years on record are all recent: 1998, $642005,2009,2010,2013,2014$ and 2015; the present year, 2016, thus far, exceeds all 65 records. The hockey stick graph is but one aspect of much more detailed reports of the 66 Intergovernmental Panel on Climate Change (IPCC) which was established by the United 67 Nations in 1988 to study climate change. However, the hockey stick graph is perhaps the 68 one piece of information that is distilled from these reports to communicate a complex 69 topic to the general public, including policy makers, the media, and even scientists in 70 other fields. Although suitable to communicate a complex topic to the general public, the 
71 hockey stick graphs presents an observational relationship without a detailed mechanistic

72 understanding of the phenomenon. In many of these same public policy forums, it is

73 often mentioned that the science of climate change is 'settled', in that there exists an

74 overwhelming consensus among scientists that human activities are responsible for these

75 changes, with fossil fuel emissions believed to be the proverbial "smoking gun". For

76 many scientists outside the direct field, those that lack the time to dig deeply into complex

77 models, this perhaps stand at odds with one's ideal notion that no scientific law is ever

78 'proven'. Certainly, an observational relationship without mechanistic understanding 79 does not represent scientific 'proof' by traditional definitions of scientific study, because

80 that is never possible (as exemplified by Newton's laws, which were replaced in the 20th

81 Century by relativity and quantum mechanics). In this paper, we attempt to provide this

82 mechanistic understanding with a "derivation" of climate and climate change, using basic

83 scientific principles. This leads to a discussion of how that temperature varies over time,

84 which is one of the characteristics associated with the much discussed "climate change".

85 Using a similar approach, we then analyse the carbon mass flux through the environment, 86 and use this as a starting point to discuss various carbon remediation strategies that have 87 been proposed.

88 
Calculations of the Earth's temperature were first carried out in the early 19th Century by

91 the mathematical physicist Joseph Fourier. ${ }^{3, *}$ Similar to the consideration below, these led

92 to a result that was much colder $\left(35^{\circ} \mathrm{C}\right.$ or $\left.63^{\circ} \mathrm{F}\right)$ than the actual temperature of the Earth.

93 As a result, Fourier's theory was not accepted, however plausible was his methodology.

94 This discrepancy was corrected some 40 years later, when John Tyndall discovered

95 experimentally that gases like $\mathrm{CO}_{2}$ and $\mathrm{H}_{2} \mathrm{O}$ play an essential role in controlling climate. ${ }^{4}$

96 This modification later came to be known as the greenhouse effect and highlights the

97 critical role played by atmospheric gases in warming a planet. Subsequent generations of

98 scientists have explored these basic ideas with increasingly sophisticated models. Notable

99 among these early pioneers was Svante Arrhenius, who was able to explain, in principle,

100 both those periods when our Earth is comfortably warm and the colder periods, like the

101 Ice Ages.

102 Fourier's simple model, with later adaptations by Tyndall and others, is presented below

103 as a first-order approximation of the energy balance on the Earth, showing how the

104 composition of the atmosphere is used to determine a planet's temperature from first

105 principles.

$106 \quad 2.1$ Energy In

107 The Sun's radiation (light) is by far the most important source of energy input for our

108 Earth. Fig. 1 presents the spectral irradiance ${ }^{\dagger}$ of the Sun, defined as the amount of light

109 that arrives at the Earth per second, per unit wavelength, as a function of wavelength. The

\footnotetext{
* Fourier's calculation was carried out in the spirit of that presented here, but differ because the correct solar spectrum was not known until it was derived by Max Planck in 1900 (on the basis of experimental data).

${ }^{\dagger} \mathrm{A}$ java applet showing the spectrum of radiation emitted as a function of the source temperature is found at http://phet.colorado.edu/en/simulation/blackbody-spectrum.
} 
110 peak intensity of the Sun's radiation lies within the visible region of the electromagnetic

111 spectrum, ranging from 400 to $700 \mathrm{~nm}$, as shown by the shaded region in Fig. 1. The

112 vision of most animals (not living underground or deep in the ocean) is particularly

113 sensitive to the wavelength region provided in greatest abundance by our Sun. In

114 particular, human vision has evolved so that it can detect only wavelengths from 400 to

$115700 \mathrm{~nm}$.

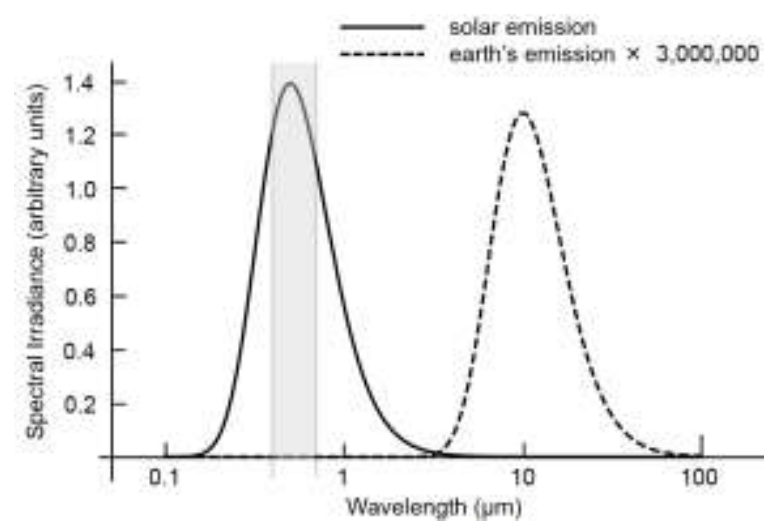

Figure 1: Intensity of radiation, as a function of wavelength, arriving at the Earth from the Sun (solid curve) and that emitted by the Earth (dashed curve). The Earth's emission curve (centred on $10 \mu \mathrm{m}$ ) has been multiplied by a factor of 3 million. The shaded area represents the visible region of the spectrum, cantered on $0.5 \mu \mathrm{m}$. From Cole et al., Science of the Earth, Climate and Energy, ${ }^{1}$ and used with permission.

117 There is negligible energy loss of the Sun's energy as it radiates outward through the near 118 vacuum of space. Thus, the rate of energy emission of the Sun, E (energy/time), is 119 essentially a constant. ${ }^{\ddagger}$ However, as with any source of energy, it disperses as it spreads 120 outwards. The relationship between the energy emitted and the flux $J(r)$ in radial 121 coordinates is:

$$
\mathrm{E}=\mathrm{J}_{\mathrm{o}}\left(\mathrm{r}_{\mathrm{o}}\right) *\left(4 \pi \mathrm{r}_{\mathrm{o}}{ }^{2}\right)=\mathrm{J}(\mathrm{r}) *\left(4 \pi \mathrm{r}^{2}\right)
$$

\footnotetext{
$\$$ The solar radiation exhibits an 11 year solar cycle of variation, of relative magnitude about $0.1 \%$, known from hundreds of years of sunspot observations.
} 
123 Where $r_{o}$ is taken as the radius of the Sun ( 432,000 miles), and $r$ is some arbitrary 124 distance away from the Sun. The flux at the surface of the Sun is related to its 125 temperature $\left(\mathrm{T}_{\mathrm{s}}\right)$ via the Stefan-Boltzmann Law:

$$
\mathrm{J}_{\mathrm{o}}\left(\mathrm{r}_{\mathrm{o}}\right)=\sigma \mathrm{T}_{\mathrm{S}}^{4}
$$

127 Here $\sigma$ is the Stefan-Boltzmann constant, with a value of $5.67 \times 10^{-8} \mathrm{~W} /\left(\mathrm{m}^{2}-\mathrm{K}^{4}\right)$. 128 Combining Eqns. 1-2, the flux from the Sun at any radial position is given by:

$$
\mathrm{J}(\mathrm{r})=\sigma \mathrm{T}_{\mathrm{S}}^{4} *\left(\mathrm{r}_{\mathrm{o}} / \mathrm{r}\right)^{2}
$$

The distances in our solar system are vast. The Earth's diameter is over 100-fold smaller than that of the Sun, and the distance between the Sun and Earth (93 million miles) is over 11,000 times that of the Earth's diameter. Thus, the rays emitted by the Sun may be taken to be of nearly parallel incidence upon arrival at the Earth. One will note that the rays strike one point on the Earth directly from above, while no radiation strikes the side 135 of the Earth experiencing night time. The global average solar radiation per unit area equals the flux from the Sun times its cross-sectional area at the equator $\left(A_{E}=\pi r_{E}^{2}\right)$ 137 divided by the surface area of the Earth $\left(A_{S}=4 \pi r_{E}^{2}\right)$. Dividing $A_{E}$ by $A_{S}$ leads to a factor 138 of $1 / 4$, meaning that the average energy flux to the Earth is equal $1 / 4^{\text {th }}$ that of the energy 139 flux incident at the Equator:

$$
\mathrm{J}_{\mathrm{in}, \mathrm{avg}} \sim \mathrm{J}(\mathrm{r}) * \mathrm{~A}_{\mathrm{E}} / \mathrm{A}_{\mathrm{S}}=\sigma \mathrm{T}_{\mathrm{S}}{ }^{4} *\left(\mathrm{r}_{\mathrm{o}} / 2 \mathrm{r}\right)^{2}=340 \mathrm{~W} / \mathrm{m}^{2}
$$

141 In the above equation, the temperature of the Sun's corona, ${ }^{\S} \mathrm{T}_{\mathrm{S}}$, is known to be $5,800 \mathrm{~K}$ 142 from Wien's displacement law, which relates the observed maximum intensity

\footnotetext{
$\S$ The corona is the outermost region of the sun, the source of the radiated energy we observe. Radiation from the Sun's interior is at much smaller wavelengths (because the interior is several hundred times hotter than the corona) but that radiation does not penetrate through this outer layer.
} 
143 wavelength of electromagnetic radiation (i.e. Fig. 1) to the temperature of its source; a

144 value of $\lambda_{\max }$ of $\cong 0.5 \mu \mathrm{m}$ (see Fig. 1) has been used.

145 In addition to the Sun's radiation, a number of other cosmic sources transfer small 146 amounts of energy to the Earth. The solar wind is a stream of particles emitted by the

147 Sun, consisting of energetic electrons and protons which travel to Earth. ${ }^{* *}$ The Earth also 148 receives very small amounts of radiant energy from stars and from our Moon. Cosmic 149 rays are energetic particles from outside of the solar system, which were critically 150 important in producing the planet we stand upon because they include atoms heavier than 151 carbon, which are extremely rare in the universe. However, these sources convey a 152 negligible amount of energy relative to that transferred by the Sun.

153 On the surface of the Earth, there arise a number of factors that contribute to temperature 154 fluctuations, including the so-called El Niño (La Niña) events, which unbury (bury) 155 surface heat below the ocean surface. These effects tend to average out over decade-long 156 periods; furthermore, the model discussed here considers only the average temperature of 157 the Earth, such that these "mixing events" provide only spatial but no appreciable 158 temporal variations.

159 Geothermal energy, including volcanic activity, is a result of radioactive decay within the 160 Earth's core, slow densification of the Earth, and the resulting friction between sub161 surface rocks. On average, the geothermal energy flux is roughly $75 \mathrm{~mW} / \mathrm{m}^{2}$ at the surface, 162 about $0.03 \%$ of the solar energy flux arriving at the Earth's surface. Due to its small 163 relative magnitude, geothermal energy is ignored in the development of the simple model.

\footnotetext{
** This stream can be "detected", either directly or indirectly, through its disruptive effects on communications on Earth (due to solar storms), through the aurorae (polar lights) and through the tails of comets (which always point away from the Sun).
} 


\subsection{Energy Out}

165 Like the Sun, the Earth emits energy into space via electromagnetic radiation, although 166 this fact is not well known to nonscientists. As before, the flux of radiant energy emitted 167 from the Earth's surface, $\mathrm{J}_{\text {out }}$, is given by the Stefan-Boltzmann relation:

$$
\mathrm{J}_{\mathrm{out}}=\sigma \mathrm{T}_{\mathrm{P}}^{4}
$$

170 Where $T_{P}$ is taken as the average temperature of the planet. Clearly, the Earth's

171 temperature has large spatial and temporal variations, but for the sake of developing a 172 simple model, we first consider only the Earth's global average temperature, ignoring 173 temporal and spatial variations (consistent with the preceding treatment of the incident 174 energy).

175 It comes as a surprise to many that the Earth emits electromagnetic radiation. As the 176 Earth's surface is about 20 times $^{\dagger \dagger}$ colder than the Sun's surface, the wavelengths of the 177 Earth's radiation lie in the infrared region, centred on a wavelength about $10 \mu \mathrm{m}$ (See Fig. 178 1), invisible to the naked eye. The intensity of the radiation of the Earth is also much less 179 than $\left(\sim 1 / 3,000,000^{\text {th }}\right)$ that of the Sun, as shown in Fig. 1.

\subsection{Energy Balance}

182 The energy balance on the Earth can be written as follows:

$$
\Delta \mathrm{E}_{\text {earth }}=\mathrm{E}_{\text {in }}-\mathrm{E}_{\mathrm{out}}
$$

\footnotetext{
${ }^{\dagger \dagger}$ The Sun's corona (which produces the light we see) is about 5,800 K, while we are at about $290 \mathrm{~K}$. The Sun's interior at millions of K, but that super-hot radiation doesn't make it outside the Sun, but mostly gets absorbed in the interior.
} 
184 Here $\Delta \mathrm{E}_{\text {earth }}$ is the net rate of energy accumulation of the Earth, $\mathrm{E}_{\text {in }}$ is the incident solar 185 radiation, and $\mathrm{E}_{\text {out }}$ is the radiant energy emitted by the Earth back into space. These two 186 variable are defined in terms of flux by Eqs. 4-5 (with $\mathrm{E}=\mathrm{J} *$ Area).

187 As a first step, we consider the steady state approximation, such that $\Delta \mathrm{E}_{\text {earth }}=0$. To justify 188 this approximation, we note that the temperature of the Earth has varied only a few 189 degrees over the half-million year period for which we have a good temperature record. ${ }^{5}$ 190 The steady state approximation is then:

$$
\mathrm{E}_{\text {in }} \sim \mathrm{E}_{\text {out }}
$$

192 Using the average solar incidence defined above, and considering the flux to/from the 193 Earth at a fixed radial distance, leads to:

$$
\mathrm{T}_{\mathrm{P}}=\mathrm{T}_{\mathrm{S}} *\left(\mathrm{r}_{\mathrm{o}} / 2 \mathrm{r}_{\mathrm{P}}\right)^{1 / 2}
$$

195 This equation predicts the temperature of the Earth to be $278 \mathrm{~K}$, slightly less than 196 temperature records showing the average temperature to be $289 \mathrm{~K}$. Given the fair number 197 of approximations, this estimate seems to be fairly good, but like Fourier's original 198 model, the temperature is too cold.

199 Generalizing Eq. 8 to other planets yields average temperatures of $450 \mathrm{~K}$ for Mercury, $200322 \mathrm{~K}$ for Venus, $278 \mathrm{~K}$ for Earth, and $223 \mathrm{~K}$ for Mars. Notably, Eq. 8 predicts the 201 average temperature of the planets should decrease with increasing distance from the Sun. 202 However, the corresponding actual surface measurements are $440 \mathrm{~K}, 737 \mathrm{~K}, 288 \mathrm{~K}$, and $203208 \mathrm{~K}$. The experimentally determined values do not correlate with distances from the 204 Sun: Venus is the hottest planet, even though Mercury is the closest to the Sun. This 205 discrepancy suggests that a key feature in the model, is yet to be considered. The origin of 206 this discrepancy is the greenhouse effect. 


\subsection{The Greenhouse Effect}

208 Gardeners and vegetable growers in northern latitudes are likely to be familiar with the 209 wonders of a greenhouse, which permits plants to grow year-round. These plants are 210 beneficiaries of the greenhouse effect, by which the temperature inside a greenhouse is 211 much warmer than the ambient temperature outside. Also familiar is the analogous 212 phenomenon of the interior of a car in the summer sun: with its windows closed, the 213 interior becomes significantly warmer than the outside environment. The reason for this 214 phenomenon is that the walls of a greenhouse and the windows of a car allow most 215 inbound solar radiation to enter, but prevent most outward-bound radiation from passing 216 out, essentially acting as a one-way door, trapping the energy inside the greenhouse or car 217 so as to warm the interior.

218 The windows of a greenhouse and car are able to act this way because the incident 219 radiation is at a very different wavelength than that of the thermal radiation inside the 220 body and because the transmission properties of the glass are strongly dependent upon the 221 wavelength. Consider, for example, Fig. 2, which shows the fraction of incident radiant 222 energy that is transmitted through a typical glass window, as a function of the radiation's 223 wavelength. One sees that more than 80 per cent of the visible light $(400 \mathrm{~nm}<\lambda<700$ $224 \mathrm{~nm}$ ) passes through the glass. In contrast, the transmittance of thermal radiation, with a 225 wavelength typically exceeding 2,500 $\mathrm{nm}$ falls to nearly zero. A simple energy balance 226 analysis of the greenhouse or the car (ignoring convective flow of air due to ventilation) 227 would show energy coming in, but little or no energy coming out. 


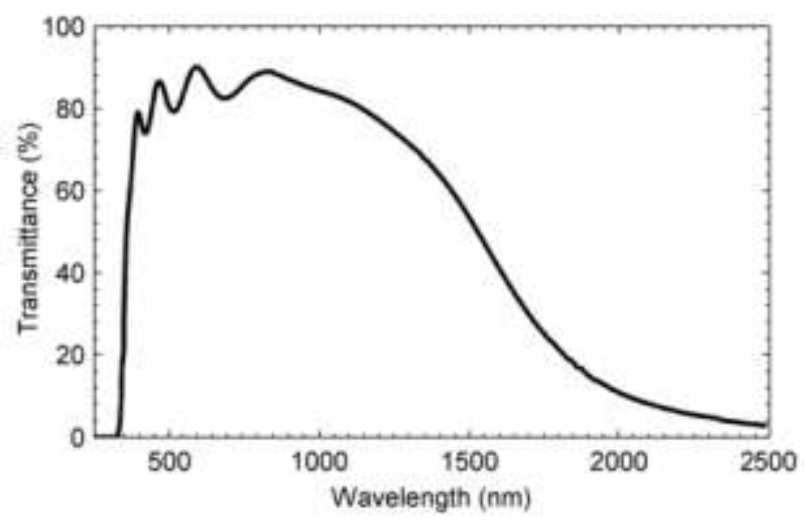

Figure 2 Transmission percentage of electromagnetic radiation through AZO glass (zinc oxide with added aluminium) as a function of wavelength. In the visible light region (400-700 $\mathrm{nm}$ ), about $80 \%$ of the radiant energy is transmitted; the transmission drops to $0 \%$ at wavelengths $>2500 \mathrm{~nm}$. From adapted from Cole et al., Science of the Earth, Climate and Energy, ${ }^{1}$ as adapted from Ref. 40; used with permission.

229 The atmosphere blanketing the Earth behaves in a remarkably similar manner, allowing incident solar radiation in the visible region largely to pass through, while absorbing a 231 fraction of the thermal infrared radiation emitted by the Earth back into space. The 232 wavelength at which a particular gas absorbs radiation is dependent upon its molecular 233 structure and the frequencies at which it vibrates. Gases that absorb in the infrared region 234 of the electromagnetic spectra trap the Earth's emitted infrared radiation, essentially 235 serving as a blanket of the Earth. Gases that absorb in the infrared region include carbon 236 monoxide $(\mathrm{CO})$, methane $\left(\mathrm{CH}_{4}\right)$, nitrous oxide $\left(\mathrm{N}_{2} \mathrm{O}\right)$, ozone $\left(\mathrm{O}_{3}\right)$, water $\left(\mathrm{H}_{2} \mathrm{O}\right)$, and 237 carbon dioxide $\left(\mathrm{CO}_{2}\right)$. This is illustrated in Fig. 3: the solid line represents the energy 238 flux that would occur if there were no greenhouse effect; one will note the various 239 greenhouse gases that absorb this radiation, decreasing the energy flux at certain 240 wavelengths. The contribution of these gases to the greenhouse effect depend upon their 241 concentration and relative abundance in the atmosphere, and whether or not they are 242 condensable and how they influence cloud formation and humidity. ${ }^{7}$ 


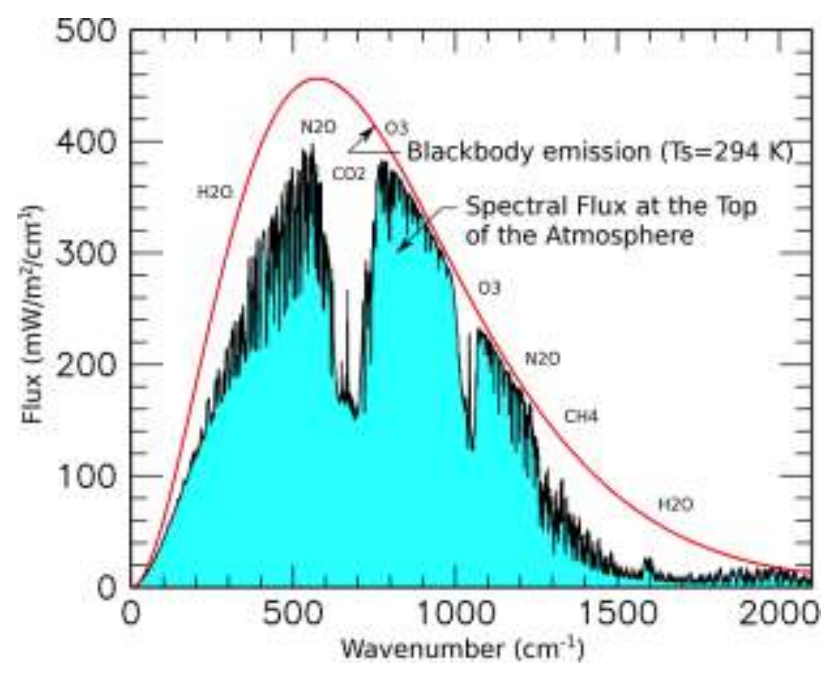

Figure 3 The Greenhouse effect: gases absorb infrared radiation, decreasing the spectral flux at the top of the atmosphere (shaded region) relative to that expected from a blackbody emission at $294 \mathrm{~K}$ (red curve). Courtesy of G. Schmidt.

244 Due to the greenhouse effect, the simple energy balance presented above must be 245 modified to account for the fraction of the radiation that is 'trapped' by the greenhouse 246 gases. This fraction of transmission is captured in an "f factor", which is determined by 247 the composition of the atmosphere, and the molecular absorbance of the gases in the 248 atmosphere. The anomalous trends discussed above for Venus is due to the composition 249 of its atmosphere, which is almost $96.5 \%$ by volume carbon dioxide, a greenhouse gas. 250 Its presence results in a much higher temperature $(741 \mathrm{~K})$ than that predicted based solely 251 on its distance to the Sun $(322 \mathrm{~K})$.

252 Just as the Earth's atmosphere may trap some of the Earth's irradiation, its cloud cover 253 may block some of the Sun's radiation from reaching the Earth. The incident energy due 254 to the Sun is modified accordingly by taking into account the Earth's albedo $(\alpha)$ which 255 represents the fraction of the total solar radiant energy incident on the Earth that is 
256 reflected back into space. The value of $\alpha$ is determined from satellite photographs ${ }^{t+}$ and

257 measurements of solar intensity reaching the Earth's surface.

258 The incident Solar irradiation and the fraction of Earth's irradiation transmitted are

259 modified in the development of the energy balance above, by multiplying each term by

260 the fraction of energy transmitted, i.e. (1- $\alpha)$ for incident radiation and (1-f) for outgoing

261 radiation, respectively. This modification leads to:

262

$$
\mathrm{T}_{\mathrm{p}}{ }^{\prime}=\mathrm{T}_{\mathrm{P}} *\left\{\left(1-\alpha_{\text {planet }}\right) /\left(1-\mathrm{f}_{\text {planet }}\right)\right\}^{1 / 4}
$$

263 In a hypothetical situation in which a planet lacks any atmosphere and reflects no incident 264 light from the Sun, both $\alpha_{\text {planet }}$ and $\mathrm{f}_{\text {planet }}$ are zero, and Equation 9 reduces to Equation 8.

265 Inserting the currently accepted average values into this equation (i.e. $\mathrm{f}=0.4$ and $\alpha=0.3)^{1}$, 266 this equation yields the result $\mathrm{T}_{\text {earth }}=289 \mathrm{~K}$, which is consistent with the Earth's average 267 temperature today.

\section{$268 \quad 2.5$ Energy Imbalance or Non-Steady State.}

269 The equations above incorporated the steady state approximation. One should recognize

270 that a small deviation from steady state can yield a non-negligible accumulation of energy

271 over sufficiently long time. Beyond the scope of this document, precise quantification of

272 the net energy flows to and from the Earth include many of the so called negligible terms

273 above, including the radioactive decay of matter within the Earth and especially the

274 significant consequences of volcanic eruptions. Such complex accounting actually leads

275 to an imbalance of the energy terms. The difference between $\mathrm{E}_{\text {in }}$ and $\mathrm{E}_{\text {out }}$ in Eq. 6, is less

276 than $1 / 2 \%$ of the individual terms that are retained. Although small, the "error" in the

\# The albedo varies both temporally and spatially. It is higher than 0.3 at places where the sky is cloudy (or the ground is covered by ice) while it is somewhat lower under desert conditions of a dry, impurity-free atmosphere. 
278 cooling).

\subsection{Modern Climate Models}

280 The preceding model is a so-called one parameter, scalar description of the Earth's energy

281 balance, in that the sole variable is the Earth's average temperature. During the last half282 century of intense study, the vast increase in relevant data and the growing concern about 283 the environment have stimulated the development of much more sophisticated models. 284 These characterize the temperature as a function of three spatial variables: latitude, 285 longitude and altitude (or depth below the ocean surface). There is in addition the time 286 variable, so high quality models are truly four-dimensional. Built into each model is a 287 vast body of empirical information, as well as a solid theoretical foundation, based on the 288 equations of fluid dynamics. These latter laws describe wind and ocean currents, which 289 are influenced by the time-dependent, nonuniform temperatures and pressures, as well as 290 the Earth's rotation and fluctuations in solar radiation. At a more local level, the models 291 must characterize variables such as clouds, mountains, glaciers, forestation, lakes and 292 volcanic eruptions. At the truly microscopic level, a model needs to account for variations 293 in atmospheric composition, since it affects the greenhouse behaviour.

294 The development of such models is a gargantuan task, posing great challenges for both 295 human computation and the accumulation of observational data used to test models' 296 predictions. The Intergovernmental Panel on Climate Change (IPCC) is an international 297 program which assesses these models in terms of the observational data. The IPCC 298 reports present a continual growth in confidence in its findings that human actions are 299 significant causes of climate change, i.e., anthropogenic climate change. While every 
300 significant group of scientists in this field has issued a statement endorsing the IPCC

301 findings, there remain scientists who do not subscribe to this consensus view.

\section{The Carbon Cycle}

303 Carbon is an essential element of life, and the carbon cycle characterizes the changing 304 state of the carbon atom. In brief, photosynthesis converts inorganic carbon dioxide $\left(\mathrm{CO}_{2}\right)$ 305 in the atmosphere to sugars, carbohydrates, and other organic molecules that form the 306 basic building blocks of plants. Animals eat these plants, using the carbohydrates for fuel 307 and further converting these organic building blocks into more complex biological 308 molecules. As they breathe, the animals take in oxygen, which reacts with the sugars to 309 create the $\mathrm{CO}_{2}$ that is released to the atmosphere. When the animal eventually decays, the 310 carbon remaining in the animal's molecules is converted back to $\mathrm{CO}_{2}$, and the cycle 311 repeats.

312 Quantitative representation of the carbon cycle (Fig. 4) as a 'mass flow diagram' shows 313 both the reservoirs for carbon in the environment, as well as the mass flux between 314 reservoirs. In addition to the simple description of the carbon cycle in the preceding 315 paragraph, one will note flux to/from the ocean, which includes both organic (such as 316 algae, phytoplankton, and sea life) and inorganic carbon (such as dissolved $\mathrm{CO}_{2}$ ). 317 Although the total amount of carbon on Earth is fixed, the amount in any given reservoir 318 may change with time. One will note that the reservoirs in the diagram are not at steady 319 state, as there is generally a mismatch between the mass flows in and out of any given 320 reservoir.

321 For example, consider the atmosphere, which has 780 GT (gigatons) of carbon. This 322 carbon is very dilute, at a concentration of $0.04 \%(400 \mathrm{ppm}) \mathrm{CO}_{2}$ and trace $(\sim 1-2 \mathrm{ppm})$ 
amounts of methane. Natural flows of carbon to/from the atmosphere tend to be close to steady state, i.e. photosynthesis exceeds that of decomposition and respiration by just $2 \%$, and the flow to the ocean exceeds that from the ocean by $\sim 2 \%$. The anthropogenic carbon

326 flows include the combustion of fossil fuels and changes in land usage, at 6.3 and 1.6

327 GT/year, respectively. There is a net 3.2 GT/year flow of carbon into the atmosphere,

328 which is dominated by anthropogenic flows.

329 Importantly, the flow of carbon from fossil fuels to the atmosphere is a one-way path (the stream denoted ' $F F$ ' in Fig. 4). This is due to the mismatch between the time in which the fossil fuels were formed (i.e. millions of years) versus the time in which they have been extracted and utilized (i.e. 100-200 years). If one were to redefine the 'active system' as

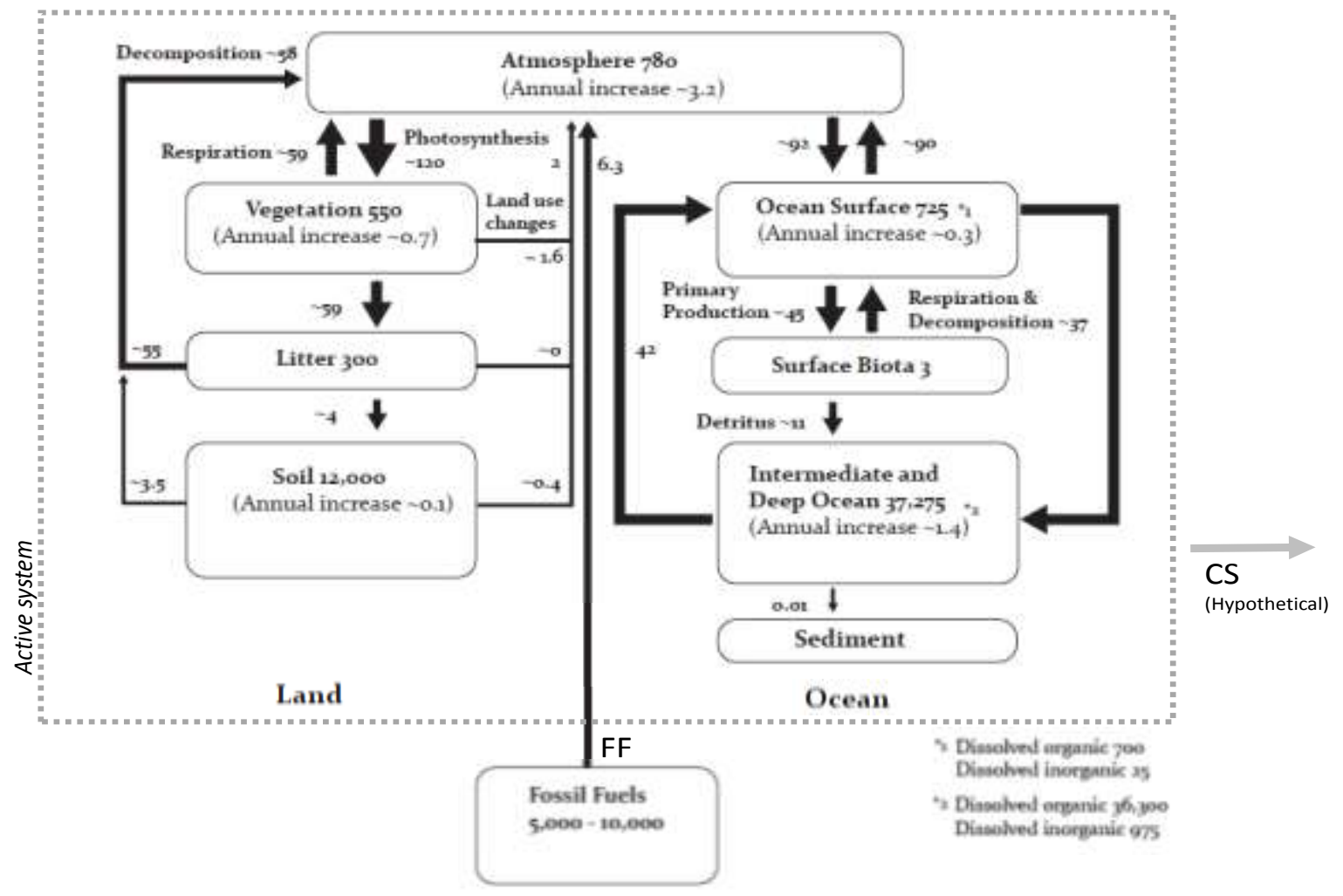

Figure 4: Mass flow diagram of the carbon cycle, showing the relative size of the carbon reservoirs (the boxes) and the flow of carbon between the boxes. Data is from the 1990s, and all values represent gigatons (billions of tons) of carbon per year. From Cole et al., Science of the Earth, Climate and Energy, ${ }^{l}$ adapted from Ref. 41 ; used with permission. 
333 the region enclosed by the dotted line in Fig. 4, this one-way flux into the new system

334 virtually ensures that the carbon concentration in the other reservoirs will continually

335 increase due to non-steady state conditions. This net influx from the FF stream explains

336 the $2 \%$ excess in natural flows out of the atmosphere, as noted in the preceding paragraph.

337 Fig. 4 suggests that 6.3 GT/year of anthropogenic carbon flow need to be removed in a

338 hypothetical carbon storage (CS) stream to return the 'active system' to steady state.

339 However, these are 1990 numbers, and the increase in $\mathrm{CO}_{2}$ concentrations in the

340 atmosphere has already led to climate change, for reasons discussed in Section I.

341 Detailed modelling suggests that several GT of $\mathrm{CO}_{2}$ have to be extracted from the 'active

342 system' to limit warming to $2^{\circ} \mathrm{C}$; more pessimistic estimates suggests tens of GT per year

343 must be removed. ${ }^{8}$ As there is uncertainty in these numbers, the discussion below treats

344 the "CS stream" as a variable referring to the carbon that must be removed from the

345 system to return to steady state conditions.

\section{Remediation Strategies: Reducing the Flux of Carbon to the Environment}

347 The goal of this section is to consider several routes by which the hypothetical CS stream 348 may significantly offset the fossil fuel (FF) stream (as illustrated in Fig. 4). The concepts 349 discussed are ranked in tiers, based on the authors' perceptions of priority, including (Tier 350 1) direct displacement of the FF stream and reduced consumption via energy efficiency 351 measures; (Tier 2) alternate routes to use fossil fuels with decreased $\mathrm{CO}_{2}$ emissions; and 352 (Tier 3) remediation strategies that have been proposed to remove $\mathrm{CO}_{2}$ from the 353 atmosphere directly. The ranking of these strategies is based on the 'mass balance' 354 vantage point outlined above, in particular, the relative fluxes and concentrations in Fig. 355 4. Specifically, one may note that removing the CS stream from any of the carbon 
reservoirs may return to the 'active system' to steady state (albeit perhaps with a

357 rebalance between the internal reservoirs).

\subsection{Tier 1A. Stop/Reduce the Carbon Flux.}

4.1.1 Carbon-Free Electricity. The most direct means to reduce the FF stream is to make

360 it obsolete, replacing the dependence on fossil fuels with carbon-free energy sources, such

361 as renewables or nuclear energy. Renewable energy includes hydroelectric energy,

362 energy derived from wood and biomass, wind energy, geothermal energy, and solar

363 energy. How the renewables are used in the economy are illustrated in Fig. 5, with the

364 current relative importance reflecting the various sectors of the U.S. economy (as an 365 example).

366 For the purposes of this discussion, the most important aspect of renewables is their 367 carbon-neutrality. Hydroelectric power provides $16 \%$ of the electricity generated in the 368 world (about 3,500 terawatt-hours in 2010). ${ }^{9}$ After a large capital investment to build a 369 dam, ${ }^{\S \S}$ the facility produces virtually carbon free energy over its lifetime (excluding 370 maintenance considerations). The energy payback periods of wind and solar energy 371 Sources are estimated to be 8 months ${ }^{10}$ and just over a year, ${ }^{11}$ respectively, with variations 372 of these estimates based on the assumptions in various life cycle analyses. Given that the 373 lifetimes of these systems are much longer than their payback periods, the energy benefits 374 for investing in these devices seems clear. Biomass can replace fossil fuels in centralized 375 combustion facilities with minimal equipment changes, although this does lead to certain 376 logistical challenges because of its low energy density. Although biomass combustion

\footnotetext{
${ }^{\S}$ Hoover Dam, for example was built in 1936 at a cost of $\$ 49$ million, roughly $\$ 700$ million in today’s US dollars. The Three Gorges Dam in China was built in 2008 at a reported cost of $\$ 37$ billion US dollars. The difference in cost can be attributed in part to size: Hoover Dam is $1350 \mathrm{MW}$, versus 22,5000 MW for the Three Gorges Dam.
} 


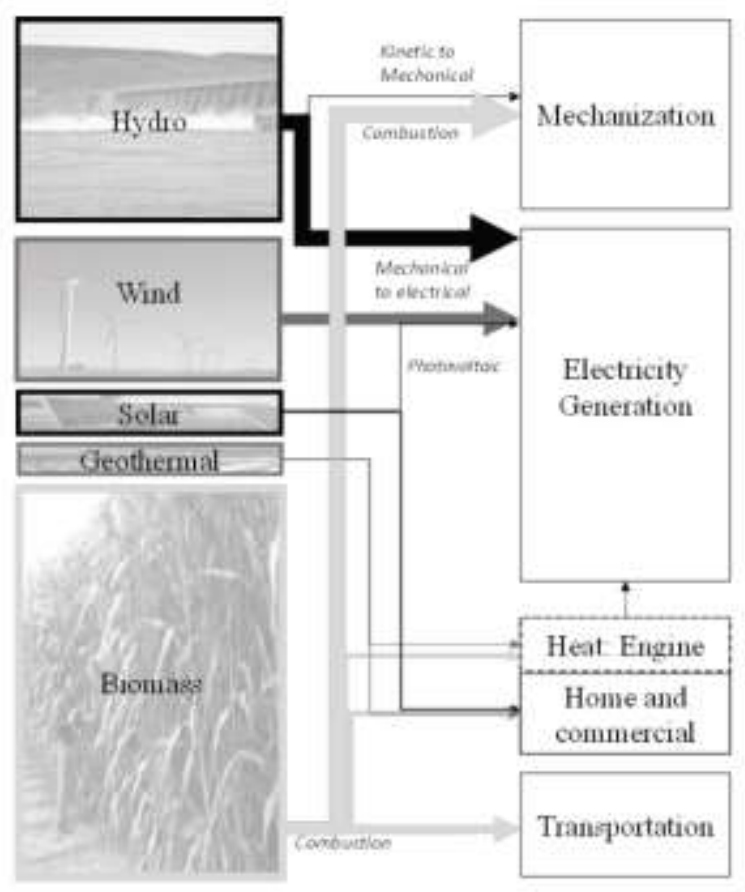

Figure 5 Schematic showing how various renewable energy sources are used. The areas of items on the left are proportional to their relative importance in the U.S. energy portfolio in 2016. From Cole et al., Science of the Earth, Climate and Energy, ${ }^{1}$ and used with permission.

377 produces carbon emissions, these are offset by the $\mathrm{CO}_{2}$ taken up by the biomass during 378 the process of photosynthesis. Thus, biomass has the potential to be carbon neutral, 379 provided that sustainable agricultural process are used that have minimal carbon 380 emissions. $^{12}$ If combined with carbon capture and storage (see below), displacing fossil 381 fuel combustion with biomass has the potential to produce negative carbon emissions 382 without a major overhaul of existing facilities, especially if waste biomass is used. ${ }^{13}$

383 4.1.2 Carbon-free transportation. The transportation sector comprises $34 \%$ of the 384 world's primary energy consumption, ${ }^{9}$ with $\sim 90 \%$ of this energy supplied by petroleum. 385 An estimated $40 \%$ of the world carbon emissions are from the transportation sector. ${ }^{14}$ 386 Capturing $\mathrm{CO}_{2}$ emissions from mobile sources is likely to be an insurmountable logistical 
387 challenge, and thus the only likely feasible solution to offset emissions from the transportation sector is to seek alternative fuels or alternative vehicles.

The only primary energy source that has the potential to offset petroleum directly, without 390 carbon emissions in today's vehicles is biomass-derived fuel. Today, ethanol and 391 biodiesel are the predominant biofuels. Biodiesel ${ }^{* * *}$ is produced by chemical 392 rearrangement of the fatty acids present in oils (like soybean, canola and sunflower oils, 393 animal fat or recycled cooking grease) by reaction with an alcohol that splits the fatty acid 394 into two smaller pieces. Ethanol is generally derived from the fermentation of cellulosic 395 biomass, i.e. the sugars and starches present in corn, switchgrass, and sugarcane. Both 396 ethanol and biodiesel are generally mixed with petroleum fuels to increase performance in 397 engines, although the amount depends upon the type of engine. There has been a 398 dramatic increase in the use of ethanol over the past decade, particularly in the United 399 States and Brazil, two countries which use twice the combined total of ethanol fuels of all 400 of the other nations of the world combined. The regional applicability of the use of 401 ethanol is due to a combination of land availability and government policies, as well as 402 technological feasibility and economic factors. For example, in the United States, corn403 producing states have lobbied Congress to mandate the inclusion of some ethanol in 404 conventional gasoline mixtures, partly rationalizing this legislation in terms of reduced 405 imports of foreign oil. Similarly, in Brazil, lacking any domestic oil supply, the 406 government has encouraged the use of all-ethanol vehicles, resulting in a higher 407 percentage of its energy from biomass than that of any other country in the world.

\footnotetext{
${ }^{* * *}$ Biodiesel should be differentiated from the use of unprocessed vegetable and waste oils in diesel engines. Use of unprocessed waste vegetable oils generally requires modification of the mechanics of the diesel engine for legal operation.
} 
408 Ethanol-blended gasoline in the U.S. typically contains about $10 \%$ ethanol, whereas 409 flexible fuel vehicles (such as those found in Brazil) are able to run on blends containing 410 about $85 \%$ ethanol.

411 Production of cellulosic ethanol is energy intensive, as biological fermentation is typically 412 low yield and requires subsequent energy-intensive separation of an azeotropic water413 ethanol mixture. Thus, the carbon neutrality of biofuels has been the subject of debate, 414 and is often dependent upon how the energy input of agricultural processes are accounted 415 for in the life cycle assessment. ${ }^{12}$ Moreover, "burning our food supply" raises ethical 416 concerns.

417 It would be much more desirable to use waste biomass instead of a food crop to produce a 418 fuel, and this problem lies at the food-water-energy nexus. Whereas biological 419 fermentation converts readily digestible sugars (such as those present in food) to alcohol, 420 metabolic engineering of microorganism that feed on [indigestible] lignin is in the 421 research stage. Yet, even ethanol is not an ideal fuel for today's automobile, and a true 422 "drop in" biofuel would be significantly lower in oxygen content, so that blending with 423 petroleum would not be required. Thermal pyrolysis to convert biomass to bio-oils has 424 been proposed as a means to develop such drop in biofuels, but water must be removed 425 from the resulting biphasic bio-oil, which is an energy-intensive and carbon inefficient 426 separation as a great deal of carbon is lost to the aqueous stream. Development of a "drop 427 in" biofuel that has performance comparable to that in today's automobile represents a 428 significant research challenge.

429 Electric vehicles provide a virtually carbon-free alternative to the internal combustion 430 engine, provided that the electricity source is dominated by carbon-free sources. Growth 
431 in the use of renewable forms of electricity and electric charging stations makes this an 432 increasingly viable scenario. Research to extend battery range, lifetime, and weight will 433 extend the range of today's electric vehicles, and make this an increasingly attractive 434 option for consumers. However, replacing all internal combustion engines with electric 435 vehicles will put a considerable demand on the existing electricity infrastructure. Methane 436 and hydrogen fuel cells have also been proposed, and have been the subject of 437 considerable government research funding across the world. In principle, hydrogen may 438 be produced from electrolysis of water powered by renewable energy, and 'renewable' 439 methane may be produced via anaerobic digestions. A hydrogen-powered transportation 440 fleet has a number of technical hurdles to overcome, including a fueling infrastructure, 441 safe on-board storage of compressed hydrogen, and costs of the fuel cell that converts 442 hydrogen to electricity. Currently, hydrogen powered transportation currently serves only 443 a limited niche market. 
446 4.1.3 Prospectus. The use of renewable energy, and in particular biomass, wind, and

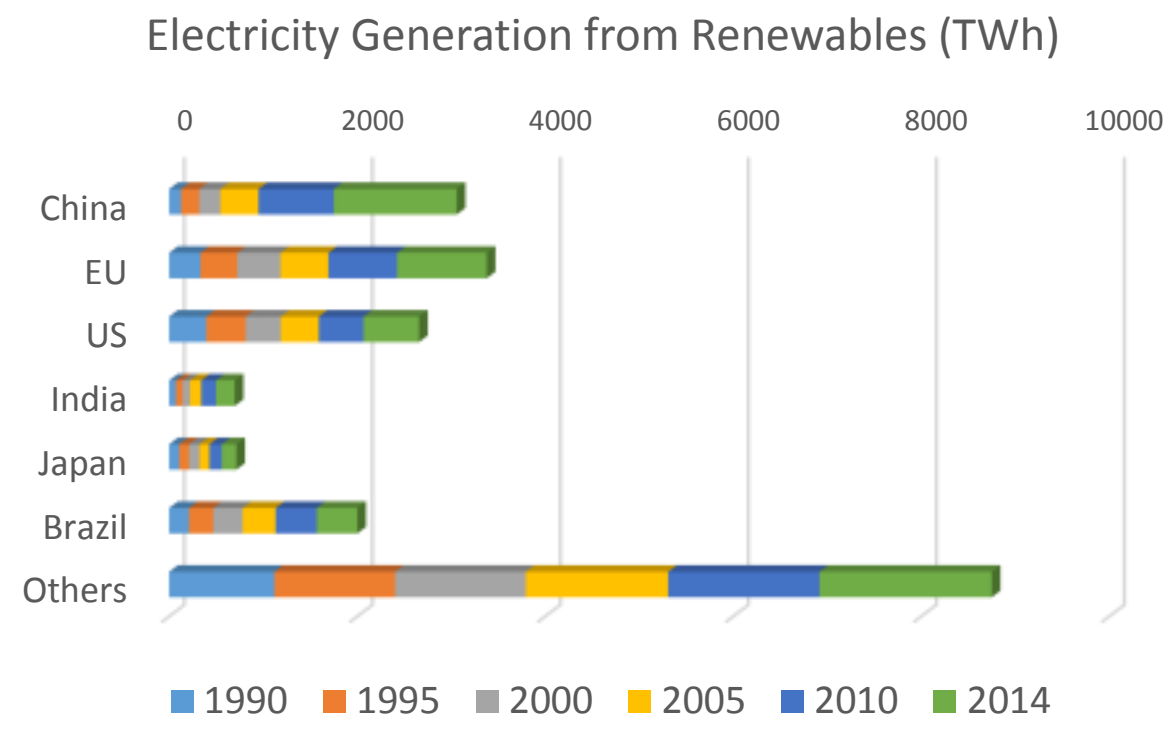

Figure 6: Electricity Generation from Renewables for various countries versus time. Data from the International Energy Agency. ${ }^{9}$

447 solar, has been increasing rapidly during the past 20 years in a number of countries (Fig. 448 6). Even in the U.S., which has historically been slow to adopt carbon treaties, 449 renewables have seen tremendous growth (see Fig. 6 and Fig. 7), driven in part by 450 policies such as the renewable energy credits at the state (rather than national) level. 451 Specifically, in 2000, $86 \%$ of primary energy consumption in the U.S. came from fossil 452 fuels, while renewables (excluding nuclear) provided just 6\%. ${ }^{9}$ In 2014 (the most recent 453 numbers available), the numbers are $81 \%$ and $10 \%$, respectively, showing a decrease in 454 the relative consumption of fossil fuels and an increase in the consumption of renewables. 455 Worldwide, the energy production numbers are relatively static over the same time 
period: fossil fuels at $80 \%$ in 2000 and $81 \%$ in 2014; and renewables at $13 \%$ in 2000 and

$45714 \%$ in $2014 .{ }^{9}$ During the same time period, the contribution of nuclear energy to the

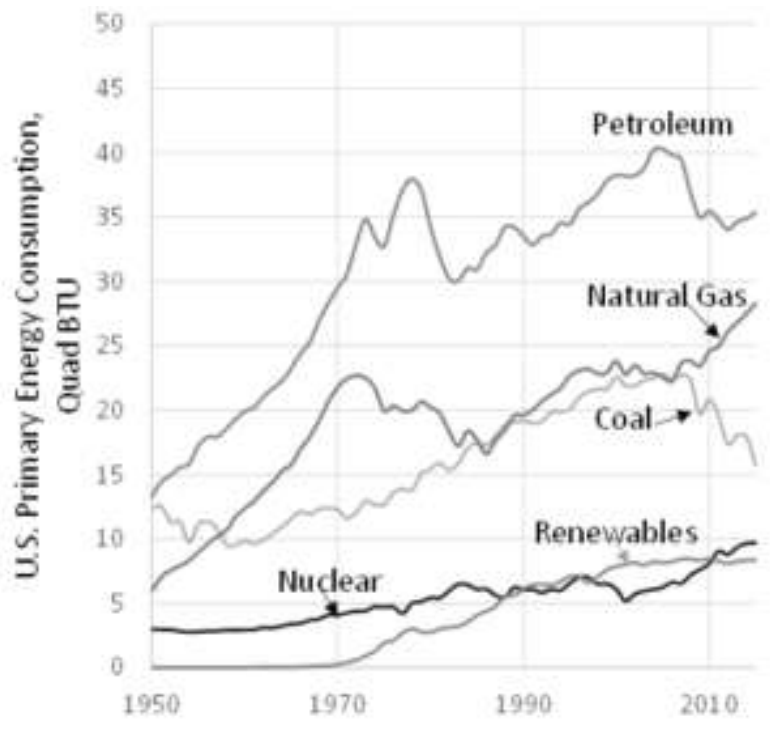

Figure 7: Primary energy used in the U.S. Data from the U.S. Energy Information, from Cole et al., Science of the Earth, Climate and Energy, ${ }^{1}$ and used with permission. energy portfolio has decreased from $12 \%$ to $11 \%$ in the U.S., and $7 \%$ to $5 \%$ worldwide.

459 Lack of growth in nuclear energy is due largely to political controversy, rather than 460 scientific or engineering challenges.

461 Despite this impressive rate of growth in renewables, Fig. 7 suggests that fossil fuels will 462 dominate the U.S.'s energy portfolio for the foreseeable future. World trends are similar: 463 despite increased use of renewables, fossil fuels continue to dominate total energy 464 production and consumption. Continued use of fossil fuels in a carbon-constrained world 465 means that we must explore means to utilize fossil fuels more sustainably, with decreased 466 carbon emissions. This has come to be known as an "all of the above" energy approach.

\subsection{Tier 1B. Reduce Carbon Emissions through Energy Efficiency}


4.2.1 Reduced Consumption. A growing integration of modern conveniences into our daily lives is increasing our personal demand for electricity, while a growing consumption

472 of consumer goods drives both commercial and industrial energy consumption, which 473 comprise $\sim 10 \%$ and $30 \%$, respectively, of the world's demand for primary energy. ${ }^{9}$

474 Residential energy represents about $\sim 20 \%$ of the world's total energy consumption, ${ }^{9}$ and 475 residential and commercial climate control make up nearly half of residential energy 476 consumption. ${ }^{\dagger \dagger \dagger}$

477 Much of this consumption is driven by consumer choice, and efforts to decrease energy 478 consumption include: (1) increasing the efficiency of automobiles, through Corporate 479 Average Fuel Economy (CAFE) rules; (2) energy efficient certifications (e.g. ENERGY 480 STAR) for home appliances to influence consumer choice; (3) design of energy efficient 481 "green buildings" that incorporate passive heating and cooling, orientation to allow for 482 natural lighting, a small external surface area to minimize heat loss to the environment, 483 and energy-efficient insulation, windows and ventilation; and (4) substitution of energy484 efficient compact fluorescent light bulbs for the traditional incandescent bulb. These 485 initiatives are making progress, but there is much work to be done. For example, the 486 American Council for an Energy-Efficient Economy ranked the U.S. 8th out of 23 487 industrial countries, ${ }^{t+}$ based on analyses of the energy efficiency within these societies, 488 with an emphasis on policy. ${ }^{15}$ Increased energy efficiency in the face of increased

\footnotetext{
${ }^{++\dagger}$ In the United States, heating and cooling represented about $50 \%$ of the total energy budget, with the remainder directed towards water heaters (about 18\%), various appliances (about 9\%), lighting (about $5 \%$ ) and electronics (about 4\%) and "miscellaneous". Data from the Energy Information Agency, October, 2015.

$\neq \neq \neq$ The countries are (in the order they are ranked for energy efficiency): Germany, Japan, Italy, France, United Kingdom, China, Spain, South Korea, United States, Canada, Netherlands, Poland, Taiwan, India, Turkey, Australia, Indonesia, Mexico, Thailand, Russia, Brazil, South Africa, Saudi Arabia.
} 
material consumption will depend on product design, labelling, education of the

490 consumer, and likely, policy that drives consumer choice.

491 4.2.2 Low Carbon Manufacturing. The influence of scientists and engineers extends 492 much farther than consumer choice and product design. Industrial activity accounts for $493 \sim 30 \%$ of the world's energy consumption. ${ }^{9}$ Historically, the energy consumption of 494 industrial facilities has taken low priority unless it played a primary role in the bottom 495 line economics. Unlike those strategies discussed in the preceding paragraph, the 496 strategies below are largely 'invisible' to the consumer. Implementation of many of these 497 strategies may be dictated by centralized policy and regulations to limit carbon emissions, 498 or economic initiatives if the price of energy rises substantially. Technological advances 499 may also spur implementation of these technologies, but there tends to be a great deal of 500 inertia due to large investments in capital equipment and current infrastructure.

501 There are a number of engineering textbooks that focus on clean manufacturing or green 502 engineering, and it is beyond the scope of this paper to describe the premises found in 503 these sources. Anastas and Warner" ${ }^{16}$ have outlined the "12 Principles of Green 504 Chemistry" that include many of the concepts outlined here (e.g. energy efficiency and 505 use of renewable feedstocks) as well as prevention of waste and incorporation of 506 inherently safer and more efficient atomistic designs into chemical synthesis. 507 Subsequently, Anastas and Zimmerman ${ }^{17}$ outlined the "12 Principles of Green 508 Engineering" and Abraham and Nguyan ${ }^{18}$ summarized the results of a conference in "The 509 San Destin Declaration of 9 Principles of Green Engineering". A number of recent 510 government funding opportunities are looking to increase energy efficiency through both 
511 "advanced" and "smart" manufacturing (e.g. in the U.S., the National Network for

512 Manufacturing Innovation, an initiative through the U.S. Department of Energy).

$513 \quad$ 4.2.3 The Chemical Industry. Beyond the general engineering initiatives and guidelines

514 outlined above, there is a growing impetus to scrutinize the high energy intensity of the

515 chemical processing industry. ${ }^{19}$ Whereas industrial activity accounts for $30 \%$ of the

516 world's energy consumption, it is estimated that $10-15 \%$ of the worldwide energy

517 consumption is devoted to separations of chemicals, ${ }^{20}$ which ultimately go into making

518 the materials we consume. This includes the necessary separation and purification of

519 industrial feedstocks that go into consumer goods, such as plastics, and even further

520 upstream, the distillation of petroleum that is the source of the feedstocks for the majority

521 of consumer goods. In the U.S. alone, the chemical industry uses the equivalent of about

522850,000 barrels of oil every day, roughly equal to the total quantity of oil used by

523 Australia. ${ }^{19}$ Although the Principles of Green Chemistry tell us we should design

524 chemical synthesis to avoid waste and energy-intensive separations through both better

525 synthesis routes and the use of highly-selective catalysts, there is clearly a practical limit

526 to the realization of this ideal.

527 In the U.S., it has been estimated that more efficient chemical separations technologies

528 could save 100 million tons $(0.1 \mathrm{GT})$ of carbon dioxide emissions, ${ }^{20}$ a significant fraction

$529(1-10 \%)$ of the targets for the CCS stream noted above, but importantly, are equivalent to

530 a 100-fold increase in the rate at which $\mathrm{CO}_{2}$ has been captured and sequestered in recent

531 demonstration facilities; the potential carbon savings is through emission avoidance.

532 A 2005 study $^{21}$ prepared for the U.S. DOE Energy Efficiency and Renewable Energy

533 (EERE) Agency surveyed potential energy savings in the chemical industry, with a focus 
534 on decreasing the significant energy consumption associated with chemical separations.

535 The study focused on the existing practices of the four largest energy-consuming 536 industries (chemicals, petroleum refining, forest products, and mining). It identified more 537 than 240 TBTU/yr that could realistically be saved by developing new or advanced 538 materials for low-energy intensity separation technologies. Many of the 539 recommendations centred on replacing energy-intensive distillation with mass separating 540 agents (membranes, adsorbents, solvents) that did not require a phase change. The basic 541 premise of this strategy is that distillation requires a high energy phase change to drive 542 separations, much of which exits the process as low-grade waste heat that is not 543 recoverable. Successful energy efficient technologies will reduce energy consumption via 544 strategies that approach the limiting thermodynamic efficiency of demixing ${ }^{\S \S \S}$ through 545 effective heat and mass process integration. For example, use of membranes for 546 desalination is cited ${ }^{22}$ as the prototypical "success story" in decreasing energy 547 consumption of a separation, as current process efficiencies approach the thermodynamic 548 limit. The efficiency gains have come about via better membrane design, but also pressure 549 recovery and integration strategies at the process engineering level. Other process (e.g. 550 pre-combustion CCS) may have opportunities for heat integration, such that a 'winning' 551 strategy cannot be easily identified without full consideration of the process flow 552 diagram.

553 The energy input to distil petroleum is the most significant input of the separation energy 554 in industry, with more energy lost in refining than is recovered in the final product sent to

\footnotetext{
$\S \S \S$ The "thermodynamics of demixing" is the difference in Gibb's free energy of a mixed solution versus that of the individual components. This includes a significant entropy component, as well as the heat of solution.
} 
555 the consumer (27 MJ lost in refining vs. $20.5 \mathrm{MJ}$ delivered to the consumer, Fig. 8).

556 Notably, the EERE report did not identify replacement of petroleum distillation as a

557 major opportunity, citing this as a mature technology with current products and

558 performance being 'cut-specific', i.e. based on the fuel vaporization in an automobile. Of

559 course, displacing petroleum provides a more direct strategy for minimizing these

560 emissions. However, petroleum-based feedstocks are the primary source of raw materials

561 in the chemical industry, used to make packaging, detergents, coatings, insulation, paint

562 and even drugs. Thus in petroleum distillation, the report focused on the significant

563 energy efficiency that can be gained in gas recovery, with opportunities to save 10

564 TBTU/year through use of membrane and absorptive separations. The chemical

565 manufacturing industry provided a much larger energy savings opportunity, where it was

566 proposed that substitution of distillation with mass separating agents could save up to 120

567 TBTU/year. The next largest opportunity (110 TBTU/year) identified was in the recovery

568 of pulping chemicals in the paper industry, through possibly preparing better filters to

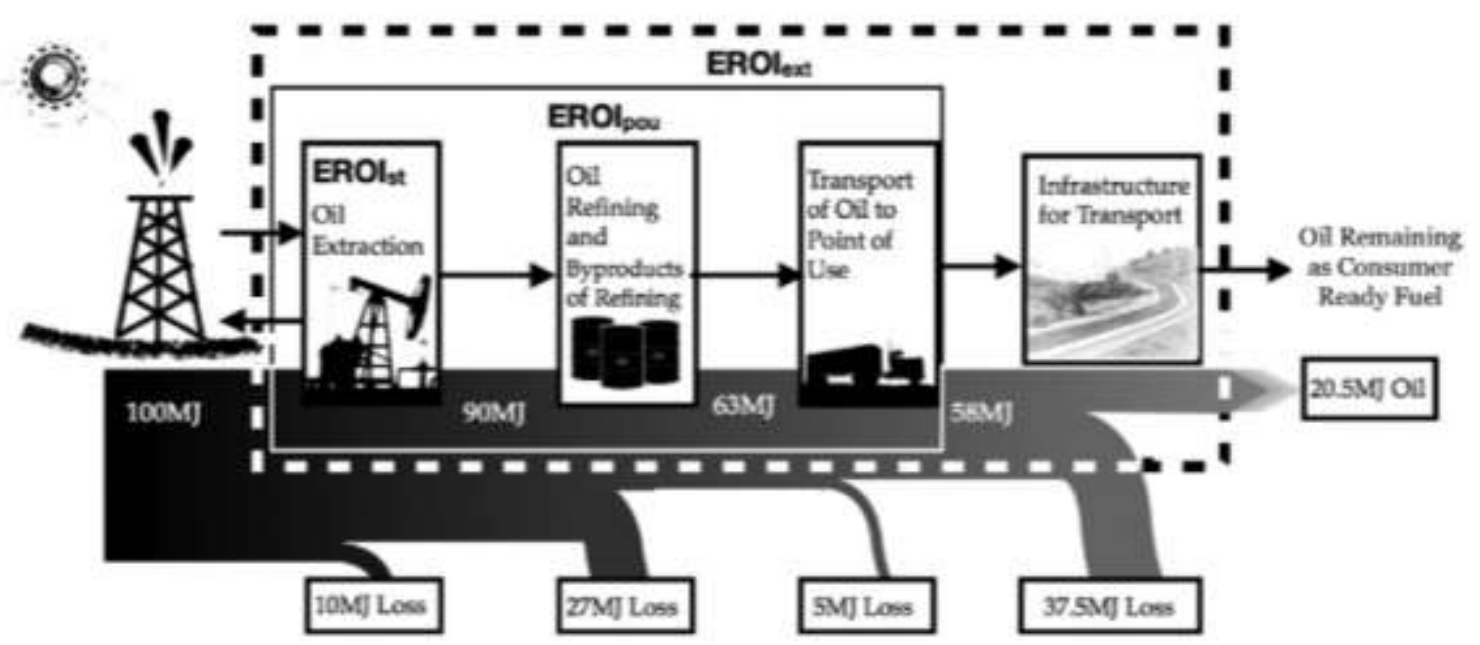

Figure 8: Energy loss associated with processing of petroleum from "well to wheel". EROI stand for energy return on investment. The energy loss at each stage of processing is shown at bottom. From Ref. 42, and used with permission. 
569 augment evaporation. Other large opportunities included oxygen enrichment, and

570 hydrogen and organic recovery from flaring practices, with 5 and 3 TBTU/year,

571 respectively.

572 Notably, many of the separations opportunities identified involve 'classic' separations 573 problems involving separating components with similar boiling points (such as 574 ethylene/ethane, propylene/propane, butadiene/butanes, styrene/ethylbenzene). Other 575 separations with potential impact include the removal of organics from water, avoiding 576 azeotripes, recovery of dilute organics from water, cryogenic separations, and polyol 577 separations (i.e. ethylene glycol/diethylene glycol, ethylene glycol / propylene glycol). 578 The success of membrane technology for approaching the thermodynamic limit for 579 energy input illustrates the potential to make use of substantial material developments in 580 the past decade to offset other significant energy inputs, and highlights the need for not 581 only scientific advances, but also integration of scientific developments into process 582 design. Although these are 'classic' separations, many emerging materials have been 583 developed in the past decade. However, implementation of these emerging materials will 584 require consideration of stability, cyclability, and chemical compatibility. The 585 importance of process integration in full energy recovery suggests that material 586 development cannot be considered in isolation. Whereas the design of a distillation tower 587 is a rite of passage in every chemical engineering curriculum, few chemical engineering 588 undergraduates are familiar with the design of membrane or adsorption processes. 589 Attainment of these alternative separation technologies will likely require reenvisioning 590 chemical engineering undergraduate education. 
4.2.4 Biorenewable Feedstocks. Use of biorenewable feedstocks was one of the 12 key 592 principles highlighted in the Green Chemistry and Green Engineering guidelines 593 mentioned above. Notably, the carbon flows to the atmosphere through the natural 594 processes of decomposition, respiration, and transfer are 10, 10, and 15-times, 595 respectively, that of the human contribution to the FF stream (see Fig. 4). Compared to 596 proposals to 'upcycle' $\mathrm{CO}_{2}$ to hydrocarbon feedstocks via carbon reutilization, the carbon 597 in these biological waste streams is already 'upcycled' (relative to $\mathrm{CO}_{2}$ ), with energy 598 input derived from the Sun's radiation via the natural process of photosynthesis. Whereas 599 the quantities of these carbon feedstocks are vast, use of renewable chemical feedstocks 600 can introduce complexities into chemical processes. The conversion of agricultural land 601 to dedicated sites for production of biorenewable feedstocks may introduce other complex 602 environmental challenges ${ }^{8}$ along with ethical concerns about energy/feedstocks 603 competing for land that might otherwise be used to drive down the cost of food for the 604 masses. Additional considerations are how the use of biorenewable crops affects the net 605 carbon balance, since the biomass acts as a carbon sink before it is harvested and crop age 606 affects the natural rate of carbon uptake and crop management can be complex to achieve 607 a net carbon sink. ${ }^{23}$ Moreover, use of carbon waste streams as feedstocks introduces 608 challenges to utilizing feedstocks with quite heterogeneous chemical structures. 4.3 Tier 2. More Efficient Use of Fossil Fuels. 4.3.1 Clean Natural Gas. Natural gas is often called "clean", because methane, the 611 principal component of natural gas, has the highest heat of combustion per unit carbon 612 atom of any carbon-based fuel. Thus, combustion of methane leads to the greatest energy 613 release per $\mathrm{CO}_{2}$ emission. In addition, natural gas has the fewest toxic mineral impurities 
614 of all fossil fuels and is much less prone to incomplete combustion, since it mixes readily

615 with gaseous oxygen. Thus, natural gas is, indeed, the cleanest burning fossil fuel.

616 Natural gas has particular regional applicability in the U.S. due to a "Shale Gas

617 revolution" that has been occurring since 2008 , spurred by a significant increase in

618 horizontal drilling techniques.

619 However, life cycle analyses of natural gas extraction, delivery, and storage suggest that

620 the environmental impact of these stages may be significant, ${ }^{24}$ although the comparison to

621 other fossil fuels is highly dependent upon the assumptions in the model, in particular,

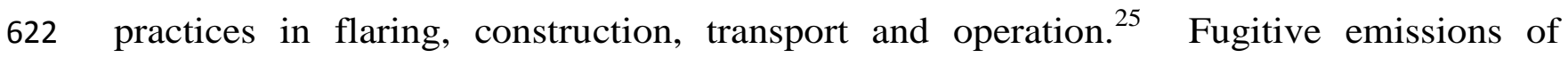

623 methane can easily offset efficiency gains during combustion, due to the increased global

624 warming potential (GWP) of methane relative to the $\mathrm{CO}_{2}$ combustion efficiency gains.

625 Quantification of methane fugitive emissions relies upon estimates, and a recent disaster

626 in Southern California involving the largest natural gas leak in the history of the United

627 States ${ }^{* * * *}$ highlights our current limits for real time detection and response to methane

628 leaks.

629 Sources of natural gas are abundant, and the domestic supply is increasing dramatically

630 (as is the associated controversy concerning environmental ramifications). Importantly,

631 natural gas may be produced via renewable sources, such as the anaerobic digestion of

632 municipal waste, and there is an increasing impetus to use this renewable natural gas to

633 fuel municipal fleets, with demonstration projects in California and Colorado. ${ }^{26}$ Storing

634 and transporting methane requires compression, which represents a parasitic energy loss

\footnotetext{
${ }^{* * * *} 97,100$ metric tons of natural gas were released during a three month period before the leak was stopped, corresponding to $5 \times 109$ cubic feet of gas, or 3\% of the facility's capacity. Nathaniel Rich, The Invisible Catastrophe, New York Times, Mar. 31, 2016.
} 
635 and transporting a compressed gas safely requires expensive carbon fibre tanks. Often,

636 methane produced in remote areas is mixed with other gases (e.g. nitrogen and/or carbon

637 dioxide), which must be removed in order to compress and transport the gas

638 economically.

639 4.3.2 Advanced Combustion Strategies. Advanced combustion strategies modify the 640 combustion process in order to both increase fuel efficiency and concentrate carbon 641 dioxide in the product to facilitate subsequent carbon capture. Advanced combustion 642 encompasses the concepts of 'clean coal', oxycombustion, gasification, and chemical 643 looping.

644 Although advanced combustion can generally be applied to any hydrocarbon, let us 645 consider methane as a representative hydrocarbon to simplify the discussion and 646 stoichiometry. First consider the "standard" combustion of methane, which is quite 647 exothermic:

$$
\mathrm{CH}_{4}+2 \mathrm{O}_{2} \rightarrow 2 \mathrm{H}_{2} \mathrm{O}+\mathrm{CO}_{2}+\text { Heat } \quad[10]
$$

649 Generally, the combustion process is completed in air rather than oxygen. If the 650 composition of air is approximated as a 4:1 ratio of $\mathrm{N}_{2}$ to $\mathrm{O}_{2}$, then the molar composition 651 of $\mathrm{CO}_{2}$ in the flue gas is $1 / 11^{\text {th }}$. This assumes complete combustion and ignores oxidation 652 of trace $\mathrm{N}_{2}$ to form nitrous oxides (NOx). In practice, excess air is used to ensure 653 complete combustion; excess air further dilutes the $\mathrm{CO}_{2}$ concentration in the flue gas, to 654 typical values of $3-13 \% .^{27}$

655 Now consider the process of gasification, which replaces oxygen with water, leading to: 656

$$
\mathrm{CH}_{4}+\mathrm{H}_{2} \mathrm{O}+\mathrm{Heat} \rightarrow \mathrm{CO}+3 \mathrm{H}_{2}
$$


657 Gasification is endothermic, as shown. Gasification is the primary means to produce 658 molecular hydrogen on an industrial scale. Gasification is also used in a number of power 659 plants, generally replacing methane with more complex hydrocarbons such as those found 660 in coal. Gasification is a means to break down a coal particle into smaller molecules (i.e. $661 \mathrm{CO}$ and $\mathrm{H}_{2}$ ) that are more readily and efficiently combusted.

662 Coal gasification utilizes high temperatures (typically $>700{ }^{\circ} \mathrm{C}$ ) and pressures to vaporize 663 and break down complex hydrocarbons. These high temperatures and pressures are 664 supplied by combining reaction [11] with reaction [10]. In other words, the exothermic 665 combustion reaction is coupled with the endothermic gasification reaction. The combined 666 reaction is known as controlled partial gasification. Adding reaction [10] with $n$ 667 reactions of [11] yields:

$$
(1+n) \mathrm{CH}_{4}+\mathrm{nH}_{2} \mathrm{O}+2 \mathrm{O}_{2} \rightarrow \mathrm{CO}_{2}+\mathrm{n} \mathrm{CO}+3 \mathrm{n} \mathrm{H}_{2}+2 \mathrm{H}_{2} \mathrm{O} \text { [12] }
$$

669 The value of $n$ is dependent upon the temperatures and pressures desired, as well as the 670 desired composition of the product stream. The product of partial gasification is synthetic 671 gas (syngas), comprised of $\mathrm{CO}_{2}, \mathrm{CO}, \mathrm{H}_{2}$, and $\mathrm{H}_{2} \mathrm{O}$. The desired composition of the 672 syngas, in particular the $\mathrm{CO}: \mathrm{H}_{2}$ ratio, is dependent upon the desired application. Syngas 673 may be converted to synthetic liquid fuels by a series of catalytic carbon addition 674 reactions, known as the Fischer-Tropsch process. Alternatively, for power production, 675 syngas should consist primarily of $\mathrm{H}_{2}$ and $\mathrm{CO}_{2}$. The $\mathrm{CO}: \mathrm{H}_{2}$ ratio of syngas is altered for 676 the desired application via the water-gas shift reaction:

$$
\mathrm{CO}+\mathrm{H}_{2} \mathrm{O} \rightarrow \mathrm{CO}_{2}+\mathrm{H}_{2}
$$


678 After [13], the syngas in a power plant consists primarily of $\mathrm{H}_{2}$ and $\mathrm{CO}_{2}$ (with some $\mathrm{H}_{2} \mathrm{O}$ 679 and $\mathrm{N}_{2}$ ). As controlled partial gasification uses less oxygen than combustion, less $\mathrm{N}_{2}$ is 680 present in the product stream.

681 In a gasification facility, $\mathrm{H}_{2}$ is separated from the other gases at high temperature and 682 pressure, where the driving force and thermodynamics of separation are increased, and 683 the $\mathrm{H}_{2}$-rich stream is sent to a combustion turbine. The resulting high-pressure, high684 temperature $\mathrm{CO}_{2}$ stream from a gasification facility is typically $\sim 40-50 \% \mathrm{CO}_{2},{ }^{28}$ roughly a 685 four to five-fold increase over a combustion process.

686 In order to further increase the $\mathrm{CO}_{2}$ concentration (to better enable carbon capture and 687 storage) $\mathrm{N}_{2}$ may be removed from the combustion process altogether, via use of chemical 688 looping or oxy-fuel combustion strategies. Oxy-fuel combustion utilizes purified oxygen 689 rather than air in the combustion chamber, further minimizing the amount of nitrogen 690 diluent, leading to a flue gas that is further enriched in $\mathrm{CO}_{2}$. Oxygen is purified from air 691 at large scales via cryogenic distillation, which is energy intensive. The highly parasitic 692 energy loss of cryogenic distillation makes this feasible only with the decreased oxygen 693 input of gasification. The incentive to purify oxygen is that this has the potential to be 694 less energy intensive than subsequent purification of $\mathrm{CO}_{2}$ from the flue gas. Emerging 695 separation technologies may change the economics of large-scale air purification ${ }^{28}$ or 696 carbon capture. An alternative to large-scale separation of air is chemical looping, which 697 delivers oxygen via oxidation-reduction cycling of a metal oxide carrier; the metal oxide 698 supplies oxygen for combustion and then is reduced by the fuel in the combustion 699 chamber. 
A significant drawback of these advanced combustion strategies is that it is not possible

701 to retrofit existing power plants with these technologies. Both oxy-combustion and

702 chemical looping require significantly higher temperatures, and thus require new 703 structural materials for the reactor, especially since these reactions occur at very large 704 scale at high pressure. Thus, advanced combustion strategies would require a major 705 reinvestment in a new infrastructure.

706 4.3.3 Carbon Capture and Storage (CCS). Short of archiving carbon-based fuels, 707 considerable reduction in carbon emissions is unlikely without capture of the $\mathrm{CO}_{2}$ 708 combustion product before it enters the 'active carbon cycle' in Fig. 4. Whether the $\mathrm{CO}_{2}$ 709 is to be utilized or sequestered, it must be purified, transported and stored; resulting 710 streams are typically $>90 \% \mathrm{CO}_{2}$ at pipeline pressures of $100-150 \mathrm{~atm}^{28-30}$ Practically 711 speaking, CCS is limited to point sources, such as those at centralized power and 712 industrial facilities. These stacks are already heavily regulated, and provide point sources 713 that are relatively concentrated in $\mathrm{CO}_{2}$. The vast majority of today's combustion facilities 714 contain up to $\sim 10 \% \mathrm{CO}_{2}$ in the flue gas (reaction [10], in $\mathrm{N}_{2}$ ), which exits the stack at 715 approximately atmospheric pressure. Thermodynamics dictates that concentration and 716 pressurization requires a significant energy input, and thus CCS strategies represent 717 significant parasitic energy losses that translate to additional fuel consumption and the 718 corresponding environmental impacts of extraction.

719 Clean coal advocates suggest that end-of-pipe devices can be put in place to capture $\mathrm{CO}_{2}$ 720 emissions, with similar success that has been seen for other air pollutants through the use 721 of end-of-pipe pollution control technologies such as baghouses and scrubbers (among 722 others). Capturing $\mathrm{CO}_{2}$ from these facilities is termed post-combustion $\mathrm{CCS}$, as it 
723 basically involves an end-of-pipe add on control technology, without modification of the

724 process itself. $\mathrm{CO}_{2}$ is scrubbed from the flue gas by injecting a basic amine-based solvent

725 (such as monoethanolamine) that chemically absorbs the $\mathrm{CO}_{2}$. This is currently the

726 technology of choice, as it is amenable to large scale and the low pressures of flue gas.

727 However, amine-based solvents are susceptible to thermal and oxidative degradation and

728 require high energy input for regeneration. ${ }^{30}$

729 4.3.4 Pre-combustion CCS strategies modify the combustion process to maximize the 730 concentration of $\mathrm{CO}_{2}$ in the flue gas, using the advanced combustion strategies outlined 731 above. In addition to increasing fuel efficiency, the increased $\mathrm{CO}_{2}$ concentration in the 732 gasification minimizes the parasitic energy expenditure of the CCS process, as some of 733 the work to concentrate the $\mathrm{CO}_{2}$ has already been done. Moreover, the separation of $\mathrm{CO}_{2}$ 734 at high pressure leads to a greater driving force for separation, and minimizes the parasitic 735 energy loss for compression and transport. The high-pressures and high-temperatures 736 used in pre-combustion CCS open up new opportunities for solvents, adsorbents, 737 membranes, or hybrid processes to capture the $\mathrm{CO}_{2}$.

738 4.3.5 Prospectus. Capture and storage of $\mathrm{CO}_{2}$ from power plants represents a significant 739 engineering challenge and a tremendous expenditure of energy. Estimates of the process 740 energy penalty for CCS include an 8-20\% drop in net efficiency for post-combustion 741 capture and a 12-20\% drop for pre-combustion CCS. ${ }^{31}$ CCS will significantly increase 742 the price of electricity; estimates are $25-40 \%$ for retrofitting new plants, to $80 \%{ }^{32}$ for 743 designing new plants. A DOE research target is to decrease this cost, such that $90 \% \mathrm{CO}_{2}$ 744 capture can be achieved with an increase in cost of $20 \%$ for post-combustion and $10 \%$ for 745 pre-combustion capture. ${ }^{33}$ Despite apparent cost savings of the latter, it requires a major 
746 reinvestment in infrastructure, money that is perhaps better spent investing in carbon-free

747 energy sources. The next obvious question is what will be done with all the stored $\mathrm{CO}_{2}$,

748 an issue addressed in the next two sections.

$749 \quad$ 4.4 Beneficial Reuse of Carbon Emissions

750 4.4.1 Carbon utilization suggests that the $\mathrm{CO}_{2}$ captured from the combustion process

751 will be put to beneficial reuse in developing or displacing other chemical feedstocks.

752 Several strategies for carbon utilization have been reviewed elsewhere, ${ }^{34}$ and include: (a)

753 coupling endothermic $\mathrm{CO}_{2}$ reforming of methane with other exothermic reactions, (b) use

754 of $\mathrm{CO}_{2}$ as a mild oxidant in industrial-scale reactions, (c) reaction of $\mathrm{CO}_{2}$ with ammonia

755 to produce a fertilizer, (d) substitution of $\mathrm{CO}_{2}$ for other reactants in production of, for

756 example, salicylic acid and dimethyl carbonate, (e) use of supercritical $\mathrm{CO}_{2}$ as an

757 industrial solvent, (f) use of a $\mathrm{CO}_{2}$-rich gas in Fischer-Tropsch synthesis of synthetic

758 liquids, or (g) hydrogenation of $\mathrm{CO}_{2}$ to methanol using 'renewable $\mathrm{H}_{2}$ ', with additional

759 'upcyling' to other hydrocarbons. Another emerging theme for carbon utilization is use of

760 biochar, a byproduct of thermal pyrolysis of biomass, for soil amendment. As shown in

761 Fig. 4, and discussed elsewhere, ${ }^{35}$ the content of carbon in the soil exceeds that of the

762 atmosphere by several-fold (estimates may vary from 5-15 times). The lifetime of soil

763 organic matter can exceed thousands of years, ${ }^{36}$ with impact on water quality and

764 retention of nutrients in the soil for fertilizing plant growth. ${ }^{36}$

765 There are several potential concerns related to the carbon utilization strategy. First, one

766 must evaluate whether a proposed strategy represents a mere delay in returning the carbon

767 to the much larger natural reservoirs, or sequestration over a much larger timescale (as

768 may be the case for biochar if it is retained for thousands of years). Additional concerns 
769 are how retention of carbon in various reservoirs may affect other ecological systems ${ }^{8}$.

770 Second, there is a significant mismatch of scale between the FF mass flow rate and the

771 scales of all other anthropogenic flows of carbon molecules. To put this issue in

772 perspective, the carbon present in the global rate of worldwide plastic production is only

$7736 \%$ of the rate that $\mathrm{CO}_{2}$ is emitted in the U.S. ${ }^{+\dagger \dagger \dagger}$

774 Third, many of these carbon utilization reactions are endothermic, and it has been 775 proposed that they may be coupled to other exothermic reactions or powered by 776 renewable energy; the proposal devalues other potential uses of this high value energy.

777 Such a proposal to reduce $\mathrm{CO}_{2}$ with 'renewable' $\mathrm{H}_{2}$ or $\mathrm{NH}_{3}$ generally involve high778 pressure, high-temperature conditions, and precious metal catalysts, as well as the input of 779 renewable energy to produce $\mathrm{H}_{2}$ or $\mathrm{NH}_{3}$, which are not naturally abundant. Even when/if 780 the considerable energy input is acknowledged, one must analyse whether this energy 781 may be more effectively used directly to offset the FF stream, for example, by producing 782 electricity to power electrical vehicles. Another consideration is whether waste biological 783 feedstocks represent a natural alternative to "upcycled $\mathrm{CO}_{2}$ ", with the energy input 784 provide by photosynthesis to convert the $\mathrm{CO}_{2}$ to a $\mathrm{CH}_{\mathrm{x}} \mathrm{O}_{\mathrm{y}}$ molecule, thus alleviating the 785 need for engineered methods to complete this conversion. For this reason, biological 786 feedstocks was discussed as a "Tier 2" strategy, whereas upgrading $\mathrm{CO}_{2}$ to $\mathrm{CHxOy}$, in the 787 authors' opinion, is a lower priority.

$788 \quad$ 4.4.2 Enhanced oil recovery (EOR) is a possible economic route for carbon utilization.

789 After hydraulic pressures are exhausted in an oil well, and physical stimulations methods

\footnotetext{
${ }^{++t+}$ According to the U.S. Energy Information Agency, 5,270 million metric tons of $\mathrm{CO}_{2}$ were emitted to the atmosphere by the U.S. in 2012. The global worldwide plastics production in 2012 was about 300 million tons in 2013 (Gourmelon, Global Plastic Production Rises, Worldwatch Institute).
} 
790 (such as water injection) have been used, more than $50 \%$ of the oil typically remains in 791 the reservoir. Enhanced oil recovery, also known as tertiary recovery, uses a chemical 792 means to recover oil from the subsurface by altering the properties of the oil. Examples of 793 chemicals that are used include nitrogen gas, steam, surfactants, and $\mathrm{CO}_{2}$, pertinent to the 794 present discussion. $\mathrm{CO}_{2}$ dissolves in the oil, altering its chemical properties, decreasing its 795 viscosity and its binding to geological media. Tertiary oil recovery methods extend the 796 lifetime of a reservoir, decrease the need for more exploratory or offshore drilling, and are 797 partly responsible for the "Shale Gas revolution" in the U.S. since 2008. A life cycle 798 analysis suggested that this is the only strategy that provides a net economic incentive for 799 CCS. $^{37}$

800 4.4.3 Carbon Sequestration. Concentrated $\mathrm{CO}_{2}$ may be removed from the active carbon 801 cycle via sequestration in giant underground caverns, such as those found in depleted oil 802 fields or in deep saline aquifers. Although creating permanent "carbon waste facilities" is 803 considered inherently unsustainable by many, carbon sequestration may provide a short804 term solution to make viable an "all of the above" energy approach in the face of climate 805 change concerns. From the mass balance perspective illustrated in Fig. 4, this concept 806 essentially involves recovering a resource, extracting its energy, and rerouting the waste 807 products back to the original reservoir. However, capturing a sizable fraction of $\mathrm{CO}_{2}$ 808 from the stack of a power plant remains a considerable engineering challenge. Moreover, 809 the assumption of carbon sequestration advocates is that major geological events will not 810 compromise these facilities and that the injection of high-pressure waste fluids into the 811 subsurface will not otherwise alter the environment. Yet, a similar assumption in the 
812 injection of wastewater fracking fluids has been disproven, due to a number of

813 environmental impacts associated with this practice. ${ }^{38}$

814 Recent demonstration projects captured and sequestered $\mathrm{CO}_{2}$ at a rate of approximately 1

815 million tons per year (in the U.S., with more worldwide), showing that sequestration in 816 underground reservoirs is technologically feasible. However, the current scale relative to 817 the demand is daunting: the 1 million tons per year captured in the U.S. is less than $8180.06 \%$ of its total carbon emissions, ${ }^{+1+}$ suggesting that 1,500 such facilities would be 819 required to sequester all $\mathrm{CO}_{2}$ for this country alone. The demonstration projects are no 820 longer in operation, as there was no financial or political incentive to continue injecting $821 \mathrm{CO}_{2}$ in the ground once the demonstration ended. The $\mathrm{CO}_{2}$ produced at these facilities is 822 now used for enhanced oil recovery.

\section{4.5 Tier 3: Clean-Up Carbon Emissions}

824 4.5.1 Direct carbon dioxide removal (CDR) may refer to either engineered or natural 825 systems that directly remove $\mathrm{CO}_{2}$ from the atmosphere. In an engineered device, large 826 quantities of atmospheric gas pass through a device that concentrates $\mathrm{CO}_{2}$. Although there 827 exist chemical technologies that retain $\mathrm{CO}_{2}$ preferentially, the thermodynamics of 828 "demixing" $\mathrm{CO}_{2}$ from the atmosphere demonstrate the energy input for accomplishing 829 this process will be significant, and moreover, as there is a small driving force for 830 engineered mass transfer separations, the scale of this endeavour will be quite large. 831 Given the large quantities of air that would need to be treated to have any appreciable 832 impact on the atmospheric $\mathrm{CO}_{2}$ concentration, engineered CDR technologies are likely to ${ }^{\ddagger \neq \ddagger \ddagger}$ According to the Energy Information Administration, the U.S. $\mathrm{CO}_{2}$ emissions from coal-fired power plants in 2014 totalled 1,570 million tons. Total $\mathrm{CO}_{2}$ emissions from all U. S. sources were 5,270 million metric tons in 2012. 
833 be cost prohibitive. A recent National Academies study also concluded that CDR 834 strategies, although potentially beneficial, are limited at present by cost and technological 835 immaturity. ${ }^{39}$

836 Natural CDR strategies include accelerating "carbonization" from the atmosphere. One 837 will note in Fig. 4, that the FF stream is relatively small compared to other natural carbon 838 flows to the atmosphere. Other strategies to remove carbon from the atmosphere include 839 afforestation, soil modification, and a significant modification of agricultural processes. 840 These strategies require tremendous land area and have other ecological concerns, 841 including the potential to alter the Earth's albedo ${ }^{8}$. The National Academies Study also 842 considered "fertilizing" the ocean to accelerate algal photosynthesis and genetic 843 modification of crops to increase the carbon uptake of plants. The study concludes that 844 such concepts involve significant uncertainties and additional environmental concerns 845 (i.e. putting chemicals into the ecosystem and genetically modified organisms), and are 846 thus controversial. The ecological impacts of such strategies are also of concern, and the

847 estimated effectiveness of these strategies has been revised downward. ${ }^{8}$

\section{Conclusions}

849 The purpose of this paper was to tie interdisciplinary concepts in energy and environment 850 to basic scientific principles, using an energy and mass balance perspective. We have 851 examined a basic one parameter, scalar description of the Earth's energy balance to 852 illustrate the relationship between Earth's temperature and the atmospheric composition.

853 The carbon cycle of the Earth is analyzed through a mass balance approach, and carbon 854 remediation strategies are considered in a tiered framework based on the potential to 855 affect the Earth's carbon balance. 
Although carbon-free energy sources, particularly renewables, should be pursued aggressively, the current rate of growth in renewable energy production suggests they will not displace fossil fuels in the foreseeable future. Thus, a more comprehensive strategy will be needed to affect the Earth's energy and carbon balance. Capturing carbon dioxide at the rates needed to offset recent climate trends is a tremendous engineering challenge. Utilizing the carbon dioxide for beneficial reuse will also be challenging at the scales needed, but increased use of biorenewable resources and enhanced oil recovery offer two promising scenarios. Of particular interest are processes that result in negative carbon emissions, such as use of biomass with carbon sequestration, drop-in biofuels, and conversion of waste into renewable methane, among others.

\section{Acknowledgements}

This material includes work supported by (while AL was serving at) the National Science Foundation.

\section{References}

1 M.W. Cole, A. D. Lueking, and D. Goodstein, Science of the Earth, Climate, and Energy. World Scientific Publishers (2016). Parts of this manuscript were adapted from this textbook, and were reprinted with permission from the World Scientific Publishing Company

2 (a) M.E. Mann, R. S. Bradley, and M. K. Hughes, Global Scale Temperature Patterns and Climate Forcing over the Past Six Centuries. Nature, 1998, 392, 779-787; (b) M. E. Mann, The Hockey Stick and the Climate Wars. Columbia Univ. Press (2012).

3 J. Fourier, Mémoire sur les Températures du Globe Terrestre et des Espaces Planétaires. Mémoires de l'Académie Royale des Sciences, 1827, 7, 569-604. English translation by 
R.T. Pierrehumbert, in D. Archer and R. T. Pierrehumbert, Eds., The Warming Papers: The Scientific Foundation for the Climate Change Forecast. Wiley-Blackwell (2011).

881

882

883

884 885

886

887

888

889

890

891

892

893

894

895

896

897

898

899

900

901
4 J. Tyndall, Further Researches on the Absorption and Radiation of Heat by Gaseous Matter. In Contributions to Molecular Physics in the Domain of Radiant Heat. Appleton (1872), pp. 69-121.

5 See, e.g., J. E. Hansen and M. Sato, Earth's Climate History: Implications for Tomorrow. NASA Science Briefs, July, 2011.

6 D. R. Williams, Planetary Fact Sheet - Metric. NASA Goddard Space Flight Center Greenbelt, MD, http://nssdc.gsfc.nasa.gov/planetary/factsheet/

7 A. A. Lacis, G.A. Schmidt, D. Rind and R. A. Ruedy, Atmospheric CO2: Principal Control Knob Governing Earth’s Temperature. Science, 2010, 330, 356.

8 P. Williamson, Scrutinize $\mathrm{CO}_{2}$ removal methods. Nature, 2016, 530, 153, and references cited therein.

9 All energy statistics cited herein are from the International Energy Agency (www.iea.org/statistics). In certain cases, energy data for the U.S. have been obtained from the U.S. Energy Information Agency (www.eia.gov), including the international data (www.eia.gov/beta/international).

10 N. D’Souza, E. Gbegbaje-Das, and P. Shonfield, Final Report, Life Cycle Assessment of Electricity Production from a Vestas V112 Turbine Wind Plant, Commissioned by Vestas Wind Systems A/S, Copenhagen, Denmark, February 2011.

11 T. Wetzel, F. Feuerstein, Update of Energy Payback Time Data for Crystalline Silicon PV Modules. Proceedings of the 26th European Photovoltaic Solar Energy Conference and Exhibition, Hamburg, 2011, pp. 3191-3195. 
12 A. Gilbert and B.K. Sovocool, Emissions accounting for biomass energy with CCS. Nature Climate Change, 2015, 5, 494-496, and references cited therein.

13 D. L. Sanchez, J. H. Nelson, and J. Johnston, D. M. Kammen, Biomass enables the transition to a carbon-negative power system across western North America. Nature Climate Change, 2015, 5, 230-234.

14 Data from the Energy Information Agency for 2014. Data is for the U.S., where carbon emissions are broken down by sector. Calculation considers energy-related carbon dioxide emissions for liquids, over the total energy-related carbon dioxide emissions.

15C. Kallakuri, S. Vaidyanathan, M. Kelly, R. Cluett, The 2016 International Energy Efficiency Scorecard, July, 2016.

16P. T. Anastas and J. C. Warner, Green Chemistry: Theory and Practice. Oxford University Press (1998), p.30.

17P.T. Anastas and J.B. Zimmerman, Design through the Twelve Principles of Green Engineering. Env. Sci. and Tech., 2003, 37, 94A-101A.

18 M. Abraham and N. Nguyen, Green engineering: Defining principles" - Results from the Sandestin conference. Env. Prog., 2004, 22, 233.

19 A. N. Liveris, Make it America. John Wiley \& Sons (2011), p. 82.

20D.S. Sholl and R.P. Lively, Seven chemical separations to change the world. Nature, 2016, 352, 435, and references cited therein.

21 BCS Incorporated and Oak Ridge National Laboratory, Materials Research for Separations Technologies: Energy and Emission Reduction Opportunities. Prepared for Industrial Technologies Program, U.S. DOE Energy Efficiency and Renewable Energy, May 4, 2005. 
925

926

927

928

929

930

931

932

933

934

935

936

937

938

939

940

941

942

943

944

945

946

947

22 (a) W.J. Koros, Evolving Beyond the Thermal Age of Separation Processes: Membranes Can Lead the Way. AIChE Journal, 2004, 50, 2326. (b) W.J. Koros and R. P. Lively, Water and beyond: Expanding the spectrum of large-scale energy efficient separation processes. AIChE Journal, 2012, 58, 2624. (c) Sholl and Lively, op cit.

23 S. C. Davis, M. Dietze, E. DeLucia, C. Fkield, S. P. Hamburg, S. Loarie, W. Parton, M. Potts, B. Ramage, D. Wang, H. Youngs, and S. P. Long, Harvesting carbon from eastern US forests: opportunities and impacts of an expanding bioenergy industry. Forests, 2012, $3,370-397$.

24 R. W. Howarth, R. Santoro, and A. Ingraffea, Methane and the greenhouse-gas footprint of natural gas from shale formations. Climatic Change, 2011, 106, 679-690.

25 M. Jiang, W. Michael Griffin, C. Hendrickson, P. Jaramillo, J. VanBriesen, and A. Venkatesh, Life cycle greenhouse gas emissions of Marcellus shale gas. Environ. Res. Lett., 2011, 6, 034014.

26 R.B. Catell and J.D. Underwood, How Garbage Trucks Can Drive a Green Future. The New York Times, Aug. 19, 2016.

27 S. Mills, Coal-fired CCS Demonstration Plants, IEA Clean Coal Centre, 2012

28 B. Suresh, R. Rubler, R., Y, Yamaguchi, and H. He, IHS Chemical, Chemical Economics Handbook, Air Separation Gases, (December 2013).

29 Carbon Capture Technology Program Plan, Clean Coal Research Program, U.S. Department of Energy, Office of Fossil Energy, (January 2013).

30 N. MacDowell, N. Florin, A. Buchard, J. Hallett, A. Galindo, G. Jackson, C. S. Adjiman, C. K. Williams, N. Shah, and P. Fennell, An overview of CO2 capture technologies. Energy and Environ. Sci., 2010, 3, 1645-1669. 
31 P. Zapp, A. Schreiber, J. Marx, M. Haines, J. F. Hake, J. Gale, Overall environmental impacts of CCS technologies-A life cycle approach. Int. J. Greenhouse Gas Control, $2012,8,12$.

32 D. Carter, Retrofitting Carbon Capture Systems on Existing Coal-fired Power Plants. A White Paper for the American Public Power Association, December 2007.

33 J.D. Figueroa, T. Fout, S. Plasynski, H. McIlvried, R. D. Srivastava T, Advances in CO2 capture technology - The U.S. Department of Energy's Carbon Sequestration Program. Int. J. Greenhouse Gas Control, 2008, 2, 9.

34 C. Song, Global challenges and strategies for control, conversion and utilization of $\mathrm{CO} 2$ for sustainable development involving energy, catalysis, adsorption and chemical processing. Catal. Today, 2006, 115, 2.

35 J. Lehmann and M. Kleber, The contentious nature of soil organic matter. Nature, 2015, $528,60$.

36 J. Lehmann et al. Persistence of biochar in soil. In J. Lehmann and S. Joseph, Eds., Biochar for Environmental Management; Science, Technology and Implementation. Second Edition. Earth Scan (2015), pp. 235-282.

37 D. Iribarren, F. Petrakopoulou, and J. Dufour, Environmental and thermodynamic evaluation of $\mathrm{CO}_{2}$ capture, transport and storage with and without enhanced oil recovery. Energy, 2013, 50, 477.

38 (a) US Geological Survey Report, A Century of Induced Earthquakes in Oklahoma? Released October 20, 2015; (b) This report was based on an article with the same title, by S. E. Hough and M. Page, Bulletin of the Seismological Society of America, October 20, 2015. 
97139 National Academies Reports, (a) Climate Intervention: Reflecting Sunlight to Cool Earth:

972 Reflecting Sunlight to Cool Earth, 2015; (b) Climate Intervention: Carbon Dioxide

973 Removal and Reliable Sequestration, 2015.

97440 R. J. Mendelsberg, S. H. N. Lim, Y. K. Zhu, J. Wallig, D. J. Milliron, and A. Anders, 975 Achieving high mobility $\mathrm{ZnO}$ :Al at very high growth rates by dc filtered cathodic arc 976 deposition. J. Phys. D: Appl. Phys., 2011, 44, 232003.

97741 R. A. Houghton, Balancing the global carbon budget. Ann. Rev. Earth and Planetary Sci., $978 \quad 2007,35,313$.

979 42 C.A.S. Hall, J. G. Lambert, and S. B. Balogh, EROI of different fuels and the 980 implications for society. Energy Policy, 2014, 64, 141. 